\title{
PEMANFAATAN SENSOR ULTRASONIK BERBASIS ARDUINO UNO SEBAGAI PERINGATAN DINI BANJIR BENGAWAN SOLO DI KABUPATEN TUBAN, JAWA TIMUR
}

\author{
Alif Putra Lestari ${ }^{1}$ \\ ${ }^{1}$ SMA Muhammadiyah 10 Surabaya \\ Jl. Genteng Muhammadiyah 45 Surabaya, Jawa Timur \\ ${ }^{1}$ Program Magister Pendidikan Geografi, Sekolah Pascasarjana, UNESA, \\ Jl. Lidah Wetan, Lakarsantri, Surabaya, Jawa Timur 60213
}

Abstrak : Bengawan Solo merupakan salah satu sungai besar yang membentang dari Jawa Tengah hingga Jawa Timur. Pada Desember 2007 luapan Bengawan Solo menyebabkan banjir besar. Sementara selama ini tidak ada penanda atau peringatan dini ketika Bengawan Solo meluap. Peneliti mengajukan pemanfaatan sensor ultrasonik berbasis arduino uno sebagai peringatan dini banjir Bengawan Solo di Kabupaten Tuban, Jawa Timur. Jenis penelitian yang digunakan dalam penelitian ini adalah penelitian kuantitatif dengan metode eksperimental. Sensor akan dipasang di bibir sungai di atas tiang mengahadap ke bawah, dengan indikator lampu LED dan buzzer dan akan memberikan informasi level 1, level 2, dan waspada. Penarapan sensor ultrasonik berbasis arduino uno sebagai peringatan dini banjir ini bisa menjadi alternatif dalam mitigasi bencana. Salah satu alat pendeteksi jarak ketinggian air menggunakan sensor ultrasonik dan dengan penggabungan mikrokontroler arduino uno $\mathrm{r} 3$ yang digunakan untuk memantau perubahan ketinggian air serta menampilkan informasi secara berkala (Komaludin dan Garliaji, 2014). Penerapan sensor ultrasonik berbasis arduino uno sebagai peringatan dini banjir Beangawan Solo perlu untuk dilaksanakan, tepatnya di Kabupaten Tuban sebagai daerah langganan banjir Bengawan Solo ketika musim penghujan tiba.

Kata kunci : Banjir, Sensor ultrasonik, alat peringatan dini banjir

\section{A. PENDahuluan}

Sungai merupakan sumberdaya yang menyediakan kemudahan hidup bagi masyarakat disekitarnya. Air yang ada dapat dimanfaatkan untuk kebutuhan hidup sehari-hari. Di sisi lain, masyarakat tadi juga menghadapi risiko bencana tahunan akibat banjir. Banjir dapat terjadi akibat naiknya permukaan air lantaran curah hujan yang diatas normal, perubahan suhu, tanggul atau bendungan yang bobol, pencairan salju yang cepat, terhambatnya aliran air di tempat lain. Hal ini membutuhkan strategi-strategi penanganan yang menyeluruh dan multistakeholders.

Bengawan Solo merupakan salah satu sungai besar yang membentang dari Jawa Tengah hingga Jawa Timur. Pada Desember 2007 luapan Bengawan Solo menyebabkan banjir besar. Di Bojonegoro, ketinggian papan duga mencapai 16,15 peilschaal, dan menggenangi hampir seluruh wilayah 
kota dengan rata-rata 1 meter. Di Lamongan luapan Bengawan Solo menggenangi kecamatan Glagah, Laren dan Babat, dan kecamatan Widang (Tuban) dengan ketinggian rata-rata 1 meter. Sementara di Gresik Bengawan Solo menenggelamkan ratusan hektar tambak dan sawah dan ratusan rumah di sekitar das Bengawan solo (Yulaelawati \& Syihab, 2008).

Sementara selama ini tidak ada penanda atau peringatan dini ketika Bengawan Solo meluap. Sehingga ketika terjadi banjir, warga tidak tahu atau tidak ada persiapan sebelumnya, yang berarti air luapan Bengawan Solo langsung menerjang pemukiman atau areal persawahan di sepanjang sungai. Hal ini tentunya cukup merugikan bahkan sangat merugikan warga, sebab seharusnya banjir bisa diantisipasi terlebih dahulu untuk meminimalisir kerugian yang akan didapat. Dan berikut adalah data genangan banjir Bengawan solo yang terjadi terakhir kalinya, yaitu pada bulan April 2013. Tepatnya hari Rabu, pukul 07.00 WIB untuk Kecamatan Widang Kabupaten Tuban.

Tabel 1. Data genangan banjir Kecamatan Widang Kabupaten Tuban (April 2013)

\begin{tabular}{|c|c|c|c|c|c|c|c|c|c|}
\hline \multirow{2}{*}{ No } & \multirow{2}{*}{ Desa } & \multicolumn{7}{|c|}{ Data dan wilayah tergenang } \\
\cline { 3 - 10 } & & \multicolumn{2}{|c|}{ Penduduk } & \multicolumn{3}{|c|}{ Jalan (m) } & \multicolumn{2}{c|}{ Lahan pertanian (Ha) } \\
\cline { 3 - 10 } & & Kk & Jiwa & Kab & Poros & lingk & Sawah & Tegal & Tambak \\
\hline 1 & Patihan & 405 & 1043 & - & 1700 & 600 & 15 & 3 & - \\
\hline 2 & Ngadipuro & 482 & 1684 & 1000 & - & 2975 & 40 & - & - \\
\hline 3 & Ngadirejo & - & - & - & - & - & - & - & - \\
\hline 4 & Widang & 191 & 665 & - & - & 1000 & 89 & 39 & 149 \\
\hline 5 & Banjar & - & - & - & - & - & - & - & - \\
\hline 6 & Tegalsari & 23 & 77 & - & - & - & - & 7 & - \\
\hline 7 & Kedungharjo & 25 & 85 & - & - & - & - & - & - \\
\hline 8 & Tegalrejo & 15 & 56 & - & - & - & - & - & - \\
\hline 9 & Simorejo & 18 & 54 & - & - & - & - & - & - \\
\hline & Jumlah & $\mathbf{1 1 0 8}$ & $\mathbf{4 0 2 4}$ & $\mathbf{1 0 0 0}$ & $\mathbf{1 7 0 0}$ & $\mathbf{4 5 7 5}$ & $\mathbf{6}$ & $\mathbf{1 4 4}$ & $\mathbf{1 4 9}$ \\
\hline
\end{tabular}

Sumber : Pemerintah Kecamatan Widang Kabupaten Tuban tahun 2013

Berdasarkan uraian di atas, maka penulis mengajukan sebuah penerapan alat peringatan dini banjir Bengawan Solo di Kabupaten Tuban, Jawa Timur. 
Penelitian ini berjudul "Pemanfaatan

sensor ultrasonik berbasis arduino uno sebagai peringatan dini banjir Bengawan Solo di Kabupaten Tuban, Jawa Timur". Dengan penerapan alat tersebut, diharapkan akan membantu masyarakat untuk lebih tanggap menghadapi bencana banjir Bengawan Solo, sehingga dapat meminimalisir dampak negatif yang ditimbulkan.

\section{B. METODE}

Jenis penelitian yang digunakan dalam penelitian ini adalah penelitian kuantitatif dengan metode eksperimental. Dipilihnya jenis penelitian ini karena peneliti merasa jenis ini cocok dengan penelitian yang diangkat yaitu merancang dan membangun sebuah prototype dan melakukan penelitian berupa eksperimen terhadap objek penelitian penulis. Adapun lokasi penelitian ini dilakukan di Bengawan Solo tepatnya di Kabupaten Tuban Jawa Timur. Alat yang dibutuhkan dalam penelitian ini yakni:

1) Hardware :

Mikrokontroler Arduino Uno, Sensor Ultrasonik HC-SR04, Buzzer, Lampu LED hijau kuning merah, kabel jumper, resistor, Tiang besi, Pelindung sensor, Kabel, colokan.
2) Sofware yang digunakan :

- Sofware Arduino uno

Sensor ultrasonik adalah sebuah sensor yang berfungsi untuk mengubah besaran fisis (bunyi) menjadi besaran listrik dan sebaliknya. Cara kerja sensor ini didasarkan pada prinsip dari pantulan suatu gelombang suara sehingga dapat dipakai untuk menafsirkan eksistensi (jarak) suatu benda dengan frekuensi tertentu. Disebut sensor ultrasonik karena sensor ini menggunakan gelombang ultrasonik (bunyi ultrasonik).

Pada sensor ultrasonik, gelombang ultrasonik dibangkitkan melalui sebuah alat yang disebut dengan piezoelektrik dengan frekuensi tertentu. Piezoelektrik ini akan menghasilkan gelombang ultrasonik (umumnya berfrekuensi $40 \mathrm{kHz}$ ) ketika sebuah osilator diterapkan pada benda tersebut (www.elangsakti.com).

Secara umum, alat ini akan menembakkan gelombang ultrasonik menuju suatu area atau suatu target. Setelah gelombang menyentuh permukaan target, maka target akan memantulkan kembali gelombang tersebut. Gelombang pantulan dari target akan ditangkap oleh sensor, kemudian sensor menghitung selisih antara waktu 
pengiriman gelombang dan waktu gelombang pantul diterima.
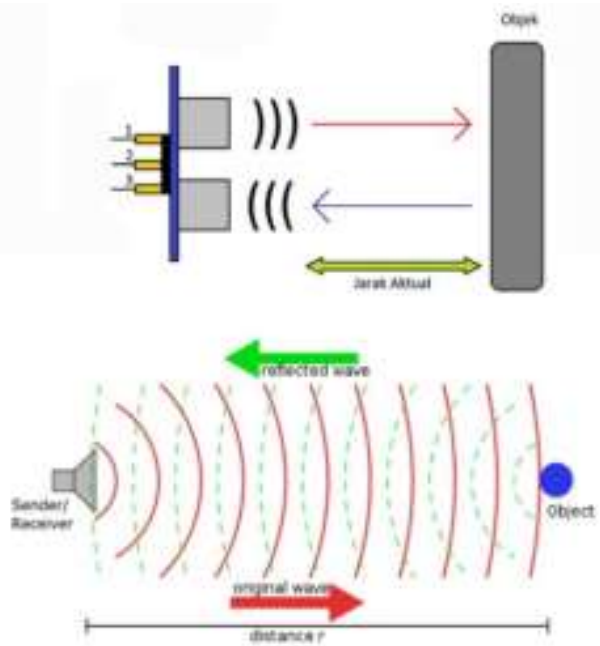

Gambar 1. Cara kerja Sensor

Kemudian hardware yang tersedia akan dirancang sesuai kebutuhan di lapangan, dengan memperhatikan kondisi titik alat akan dipasang. Pada rancangan sederhana akan nampak seperti gambar berikut :

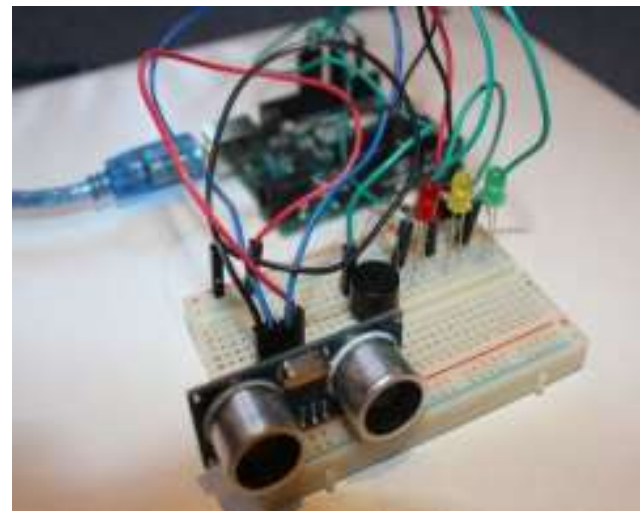

\section{Gambar 2. Rangkaian sensor ultrasonik + 3 LED + buzzer}

Sensor akan diletakkan di bibir sungai menghadap ke bawah, atau menghadap ke permukaan air sungai dengan bantuan tiang besi agar bisa menghadap secara vertikal. Jika digambarkan adalah kurang lebih seperti gambar di bawah ini :

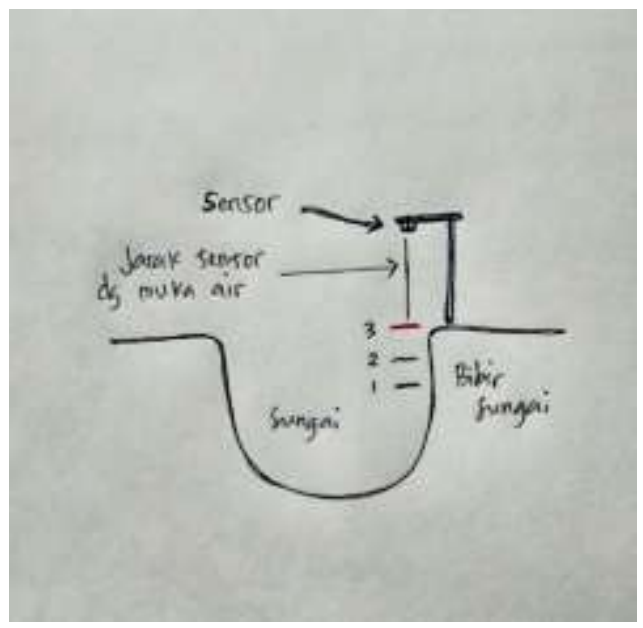

\section{Gambar 3. Rencana penempatan sensor ultrasonic}

Berdasar gambar di atas, sensor akan ditempelkan di sebuah tiang permanen untuk menjaga sensor agar tidak ikut terendam air ketika sungai meluap. Jarak sensor secara vertikal dengan bibir sungai adalah 2 meter. Sensor akan memberikan informasi jarak permukaan sungai dengan 3 level, level siaga 1, siaga 2 dan waspada. Masyarakat dapat mengetahui informasi tersebut dengan melihat indikator warna lampu LED yang menyala serta suara buzzer. Berikut adalah penjelasan indikator pada sensor : 
Tabel 2. Indikator sensor ultrasonik

\begin{tabular}{|c|c|c|c|c|}
\hline \multirow{2}{*}{ Level } & $\begin{array}{c}\text { Jarak sensor } \\
\text { dengan muka } \\
\text { air }\end{array}$ & \multirow{2}{*}{ Keterangan } & \multicolumn{2}{|c|}{ Indikator } \\
\cline { 4 - 5 } & 4 meter & Siaga 1 & Buzzer & Lampu LED \\
\hline 1 & 3 meter & Siaga 2 & Berbunyi & $\begin{array}{c}\text { Nyala warna } \\
\text { kuning }\end{array}$ \\
\hline 2 & 2 meter & Waspada & Berbunyi & $\begin{array}{c}\text { Nyala warna } \\
\text { merah }\end{array}$ \\
\hline 3 & &
\end{tabular}

Keterangan: Level 3 ketika jarak muka air sungai dengan sensor 2 meter, dimana muka air sudah sejajar dengan bibir sungai.

Jika jarak sensor dengan muka air 4 meter, maka buzzer akan berbunyi dan lampu LED akan menyala warna hijau yang berarti siaga 1. Maka kondisi di lapangan adalah muka air sungai sudah naik dan berjarak 2 meter dari bibir sungai. Siaga 2 akan berlaku jika jarak sensor dengan muka air sungai adalah 3 meter, atau jarak muka air sungai dengan bibir sungai hanya 1 meter. Jika itu terjadi maka buzzer akan berbunyi dan lampu LED akan berwarna kuning.

Lampu LED akan menyala warna merah dan buzzer tetap berbunyi, jika jarak sensor dengan muka air sungai 2 meter. Pada kondisi ini muka air sudah sejajar atau setara dengan bibir sungai dan senjutnya air akan meluap ke bantaran sungai hingga jauh. Pada level waspada ini, masyarakat sudah siap dengan terjangan air sungai yang menerjang apapun miliknya atau milik warga desa.

Selanjutnya adalah koding data yang berfungsi sebagai pengaturan di dalam software arduino uno. Sehingga perintah akan berjalan sesuai dengan yang diinginkan. berikut adalah koding dalam penelitian ini :

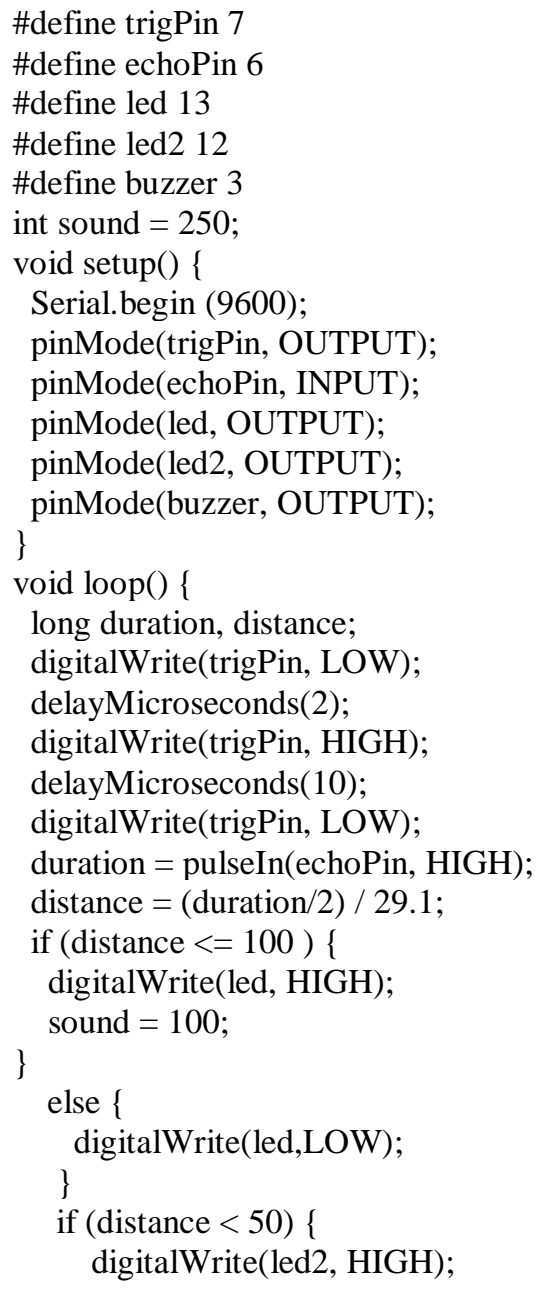




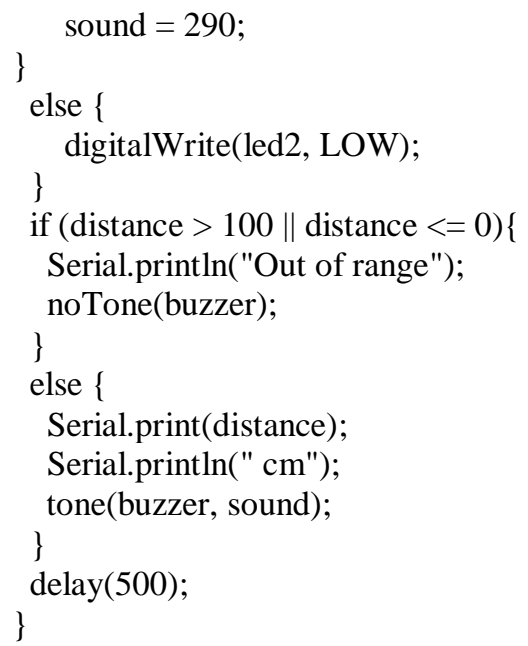

\section{HASIL DAN PEMBAHASAN}

Pemanfaatan teknologi saat ini menjadi hal yang penting di berbagai sektor, termasuk dalam bidang kajian kebencanaan. Sudah banyak teknologi yang dimanfaatkan untuk berbagai keperluan mitigasi bencana, dan mampu memberikan konstribusi yang besar bagi masyarakat selama itu dijalankan dengan baik. Pemanfaatan sensor ultrasonik sebagai peringatan dini banjir dalam penelitian ini dilakukan sebab kenyataan di lapangan belum ada yang melaksanakan.

Aprilia (2012) telah melakukan penelitian tentang sistem peringatan pendeteksi tinggi muka air menggunakan tranduser ultrasonik secara vertikal dengan tampilan LCD berbasis mikrokontroler. Penelitian dengan merancang suatu sistem peringatan dini untuk pendeteksi ketinggian air pada tampilan LCD dengan menggunakan sensor HC-SR04 sebagai pengukur jarak ketinggian air. Pendeteksi ketinggian muka air ini menggunakan catu daya sebesar 5 volt. Pada pengembalian data dilakukan dua cara pengambilan data yaitu melihat nilai data yang ditangkap oleh sensor dan langsung ditampilkan ke LCD dan melihat hasil pengukuran pada tabung.

Pada penelitian ini, jika sensor menunjukkan kondisi siaga 1, masyarakat sekitar Bengawan Solo bisa melakukan suatu usaha yang terkait dengan penyelamatan jiwa dan harta pribadi, keluarga, ataupun kelompok, terutama areal persawahan. Sebab dari banjir yang sebelumnya pernah terjadi, banyak sawah yang terendam banjir hingga para petani mengalami kerugian yang besar, terutama areal persawahan yang dekat dengan sungai. Selain areal persawahan, adalah pemukiman penduduk yang paling dekat dengan sungai karena sangat rentan terhadap banjir Bengawan Solo.

Lampu LED akan berwarna kuning dan buzzer menyala, yang berarti sungai pada status siaga 2. Pada kondisi yang demikian, masyarakat sudah harus mengambil langkah antisipasi sebab kenaikan muka air sungai bisa berlangsung sangat cepat, bergantung pada kondisi di hulu sungai. Masyarakat sudah sangat siap ketika dalam waktu sekejap sungai meluap, dan menerjang areal persawahan, perkebunan, dan 
pemukiman warga. Oleh karena itu pada kondisi ini masyarakat sudah mengamankan barang-barang berharga yang dimiliki, sehingga ketika terjadi banjir mereka tidak mengalami kerugian yang besar. Bahkan mungkin mereka pindah ke tempat yang lebih tinggi atau sementara meninggalkan rumahnya ke tempat yang lebih aman.

Sedangkan jika indikator menunjukkan level waspada, pada kondisi ini muka air sudah sejajar atau setara dengan bibir sungai dan senjutnya air akan meluap ke bantaran sungai hingga jauh. Pada level waspada ini, masyarakat sudah siap dengan terjangan air sungai yang menerjang apapun miliknya atau milik warga desa. Bahkan jika memungkinkan sudah tidak ada lagi warga yang berada di dekat sungai untuk kepentingan keselamatan, mereka sudah berada pada tempat yang lebih aman. Kemudian tim penyelamat atau tim evakuasi sudah siap melakukan tindakan yang diperlukan dan selebihnya.

Putra (2013) juga melakukan penelitian mengenai sistem monitoring data tinggi permukaan air sungai secara real time berbasis WEB dan SMS gateway. Sistem ini digunakan untuk dilakukan pemantauan terhadap data ketinggian permukaan air sungai yang diperoleh dari pengukuran sebuah tranduser ultrasonik (US) tipe HCSR04. Tranduser HC-SR04 akan mendeteksi perubahan jarak antara tranduser dengan permukaan air sungai yang selanjutnya diproses dalam mikrokontroler sehingga dihasilkan data tentang ketinggian permukaan air sungai atau kedalaman sungai, kemudian data tersebut selanjutnya dikirim ke PC server melalui alat pengkonversi port serial menjadi port USB (Univesal Serial Bus), yaitu serial to USB converter.

Penarapan sensor ultrasonik berbasis arduino uno sebagai peringatan dini banjir ini bisa menjadi alternatif dalam mitigasi bencana. Seperti di wilayah Kabupaten Tuban yang menjadi titik kajian, karena Bengawan Solo yang melewati wilayah administrasi Kabupaten Tuban merupakan faktor utama penyebab banjir di musim penghujan. Salah satu alat pendeteksi jarak ketinggian air menggunakan sensor ultrasonik dan dengan penggabungan mikrokontroler arduino uno r3 yang digunakan untuk memantau perubahan ketinggian air serta menampilkan informasi secara berkala (Komaludin dan Garliaji, 2014).

Banjir telah membunuh lebih dari 100.000 orang di seluruh dunia dan sekitar 1,4 milyar orang terkena dampak banjir hingga akhir abad 20 , serta merusak tempat tinggal, jembatan, sekolah, dan fasilitas lain (Jonkman, 2005 dalam Shen, 2010). Sebagai upaya 
untuk mengurangi dampak negatif ketika terjadi banjir, penerapan alat dalam penelitian ini di lapangan sangatlah bermanfaat. Di sisi lain, juga bisa digunakan acuan masyarakat sekitar Bengawan Solo dalam beraktivitas, sebab aktivitas keseharian mereka juga banyak yang berkutat dengan Bengawan Solo.

\section{SIMPULAN}

Berdasarkan hasil rancangan dan pembahasan di atas, maka dapat disimpulkan bahwa penerapan sensor ultrasonik berbasis arduino uno sebagai peringatan dini banjir Beangawan Solo perlu untuk dilaksanakan. Tepatnya di Kabupaten Tuban sebagai daerah langganan banjir Bengawan Solo ketika musim penghujan tiba. Di sepanjang aliran Bengawan Solo di wilayah Kabupaten Tuban, perlu dipasang sensor ultrasonik sebagai alat peringatan dini banjir, terutama di titik-titik yang paling sering mengalami banjir.

Pada penerapan di lapangan, alat yang dirancang bisa dimodifikasi sesuai dengan kebutuhan. Misalnya buzzer bisa diganti dengan alarm yang bisa mengeluarkan suara yang lebih keras agar didengar warga. Ataupun lampu LED bisa diganti dengan lampu yang lebih terang lagi sesuai kebutuhan di lapangan.

Semua rancangan dalam penelitian ini perlu dikaji dengan baik oleh Pemerintah setempat, baik buruknya sehingga penerapan bisa dilaksanakan. Perlu adanya kerjasama yang baik dari peneliti, Pemerintah setempat serta masyarakat dalam hal ini untuk mensukseskan penerapan alat peringatan dini banjir ini. Serta lebih jauh lagi, rancangan ini perlu dikembangkan lagi untuk penyempurnaan dalam hal kebermanfaatan untuk masyarakat.

\section{DAFTAR PUSTAKA}

Aprilia, Sisca. 2012. Sistem Peringatan Pendeteksi Tinggi Muka Air Menggunakan Tranduser ultrasonik Secara Vertikal dengan Tampilan LCD Berbasis Mikrokontroler. Bandar Lampung: Universitas Lampung

Https://www.elangsakti.com/2015/05/se nsor-ultrasonik.html diakses pada 2 Mei 2019

Komaludin D dan Garliaji AG. 2014. Prototype pendeteksi ketinggian permukaan air maksimum dan minimum menggunakan sensor ultrasonik berbasis mikrokontroler. JURNAL LPKIA, Vol.1 No.1, September 2014

Pemerintah Kecamatan Widang Kabupaten Tuban. 2013.

Putra, Berli Laksana. 2013. Sistem Monitoring Data Tinggi Permukaan Air Sungai Secara Real Time Berbasis SMS Gateway. Bandar Lampung : Universitas Lampung

Shen, X. (2010). Flood Risk Perception and Communication within Risk Management Different Cultural Contexts. UNU-EHS. Germany

Yulaelawati dan Syihab. 2008. Mencerdasi Bencana. Jakarta : PT Gramedia Widiasrana Indonesia. 